\title{
Transient and Mixed Convection From a Variable Tilt Angle Duct With a Built in Electric Module
}

\author{
Adnan A. Abdulrasool \\ Professor of al.Mustansyria \\ University \\ Iraq, Baghdad Province, \\ University of al.Mustansyria
}

\author{
Hadi A. Basher \\ Assist Prof. of Wasit University \\ Iraq, Wasit Province, \\ University of Wasit
}

\author{
Nagham Q. Shari \\ University of Wasit \\ Iraq, Wasit Province, \\ University of Wasit
}

\begin{abstract}
The present work represents experimental and numerical work to study the natural, transient, mixed and forced convection heat transfer from a cube which represent an electric module fixed in a relatively long duct tilted at different angles of $\theta=0^{\circ}$ (horizontal), $\theta=30^{\circ}, \theta=45^{\circ}$ and $\theta=90^{\circ}$. Module side length $(\mathrm{L}=30 \mathrm{~mm})$ fixed at different locations of $(\mathrm{X} / \mathrm{L}=5,10$ and 15$)$ with different input power of $(0.147,0.51$, $0.96,1.65,2.34$ and 3.075$)$ watt, which represent a heat flux of $(32.67,113.33,213.33,366.67,520$ and 683.33$) \mathrm{W} / \mathrm{m}^{2}$ respectively. A fan fixed at duct end is operated to move the air within the duct with different air velocities of $(0.2,0.3$, $0.5,0.7$ and 0.8$) \mathrm{m} / \mathrm{s}$ giving Reynolds number values of (381.9, 763.7, 954.7, 1336.6 and 1527.5) respectively. The system is operating in a transient heat transfer is calculated till steady state is reached. The heat transfer coefficient is estimated in this case. Testing the $\mathrm{Gr} / \mathrm{Re}^{2}$ values shows that the operating mode is in the mixed convection reaching a forced convection when operating of the highest velocity within the duct.Operating the system in transient and steady state mixed convection mode show that higher air velocities enhances the heat transfer due to giving a chance for the air to transfer the heat during its flow around the cube.
\end{abstract}

The study shows that a little effect is recognized for the module position and the tilt angle specially at mixed convection operation

\section{Nemclature}

$A_{s}$ : Surface area of cube $\left(\mathrm{m}^{2}\right), \mathrm{CP}$ : Air specific heat capacity $\left(\mathrm{J} / \mathrm{Kg} .{ }^{\circ} \mathrm{C}\right), D_{h}$ : Hydraulic diameter $(m), G_{r}$ : Grashof number, $g$ : Gravitational acceleration $\left(\mathrm{m} / \mathrm{s}^{2}\right), h$ : Convection heat transfer coefficient $\left(W / m^{2} . K\right), I$ : Electric current $(A m p), K_{a}$ : Thermal conductivity of air $(W / m . \mathrm{K}), L$ : Length of cube $(m)$, $\dot{m}$ : Mass flow rate $(\mathrm{Kg} / \mathrm{s}), \mathrm{Nu}$ : Nusselt number, $\operatorname{Pr}$ : Prandtl number $v / \alpha$, q: Input power (W), $R a$ : Rayleigh number $\frac{g \beta \Delta T L^{3}}{v \alpha}, T_{s}$ : surface temperature $(K) . T_{\infty}$ : Air temperature $(K), t$ : Time $(s), V$ : Electric voltage $(V), \beta$ : Thermal expansion coefficient $(1 / K), \vartheta$ : Kinematics viscosity of air $\left(\mathrm{m}^{2} / \mathrm{s}\right)$.

\section{Keywords}

Mixed convection in a duct, cube mixed convection, Duct heat transfer with tilt angle.

\section{INTRODUCTION}

Advanced very large-scale integration (VLSI) technology has triggered significant improvements in the performance of electronic systems in the past decades. With the trend toward higher circuit density and faster procedure speed, however, there is a steady grab hold of the dissipative heat flux at the components, themes, and system levels. That has been shown that most procedure parameters of the electronic components are highly damaged by its temp as well as their immediate thermal environment. This kind of causes an increasing demand for highly efficient digital cooling technologies to meet this demand, various electronic digital cooling schemes have recently been developed [1].

In cases of mixed convection (natural and forced occurring together) one would often like to know how much of the convection is due to external constraints, and how much is due to natural convection occurring in the system . The relative magnitudes of the Grashof and Reynolds number squared determine which form of convection dominates, [2]. If $\mathrm{Gr} / \mathrm{Re}^{2} \gg 1$ forced convection may be neglected, whereas if $\mathrm{Gr} / \mathrm{Re}^{2}<<1$ natural convection may be neglected. If the ratio is approximately one, then both forced and natural convection need to be taken into account and called mixed convection .

In common put it to use is metal object brought in to contact with an electronic component's hot surface- though in many instances, a thin thermal interface materials mediates between the two surfaces. Microprocessors and power handling semiconductors are good examples of electronics that desire a heat sink to reduce their temperature through increased thermal mass and heat dissipations (primarily by louage and convection and also to a smaller extent by radiation)[3].

W. S. Kim and M. N. Ozisik [4], 1987, studied the thermal transients in forced convection inside ductwork have numerous applications in the design of control systems for heat exchangers. In this work inductive solutions are developed for unsteady laminar forced convection inside circular tubes and parallel plate channels ensuing from a step deviation in the wall high temperature flux. The generalized integral transform technique (1974) [5] and the classical Laplace transformation are used to create a simple lowest order solution as well as increased alternatives. Kuan-Tzong Lee and Wei-MonYan [6], 1998, offered detailed numerical study to measure the effects of wall transpiration on laminar mixed convection flow and heat transfer in the access region of horizontal rectangular ducts. They found that, either wail injection or wall structure suction has some considerable impact on the flow framework and heat transfer performance. In addition, the correlating equations for the average fRe and

$\mathrm{Nu}$ are presented . Han-Chieh Chiu eta. [7], 2007, studied numerically the put together heat transfer of convection and radiation in square ducts rotating in a parallel mode. He fixed the coupled momentum and energy equations by the DuFortFrankel numerical scheme to measure the interactions of convection with radiation. This individual found that, The result of rotation in the square duct much more important than 
that within an oblong. He also show that, the radiation presents significant effects on the central distributions of the total Nusselt number, $\mathrm{Nu}_{\mathrm{t}}$, and will reduce the centrifugalbuoyancy effects. The result of rotation on the Nut is restricted in the access region, however, radiation influences the heat transfer throughout the channel. Also, the $\mathrm{Nu}_{\mathrm{t}}$ increases with the decrease in the conduction-to-radiation parameter NC

Mohamed Ahmed Saleh [8], 2008 A great experimental and theoretical exploration was carried out of heat transfer and smooth flow in a square channel by which two of its opposite walls (upper and lower walls were provided with discrete steak and heat sources. The results demonstrated the impact of the weakness of the treatment on the flow characteristics in all cases. High temperature transfer, was found on the interference effect is weak or non-existent in the case of ahead flow with the steak, while this effect was apparent in the circumstance of the flow of previous versions with steak and the case of the smooth (ribless) duct.

\section{EXPERIMENTAL APPARATUS}

The test rig and the test procedure which are carried out in order to investigate the thermal behavior of a single module $(30 \mathrm{~mm})$ side length to be fixed in different positions of a rectangular duct made of transparent plexiglass. The module is fixed at the base of the duct (lower side of the duct). The duct is designed so as it can be tilted at different angles of $\theta=0^{\circ}$ (horizontal), $\theta=30^{\circ}, \theta=45^{\circ}$ and $\theta=90^{\circ}$ (vertical). The duct is also designed with a conical portion at its end with a fan fixed at its end, so that air can be moved when operating the fan. A heater capsule is inserted inside the module (electric resistance $=201.67 \Omega$ ) so that a constant temperature, constant heat flux is the mode at which the thermal behavior investigated for the system.

\subsection{The Air Duct}

The air duct is made of plexiglass, constructed of two parts. The upper part is designed with a curved entrance, its cross section of concave downward rectangular shape. The curved entrance is shaped so as to ensure a smooth entrance of air through the duct when assembled with the lower portion which is constructed in the same way, but with a flat shape with edges of $(4 \mathrm{~cm})$ around its circumference. The upper and lower portions of the duct are of the same length, which is designed to be equal to 25 times the cube side length (i.e. 25L).

Figure 1 shows a Test rig with accessories.

The exit of the duct is fixed with a conical portion of (10L) $(300 \mathrm{~mm})$ length so that a low power DC fan is fixed at the middle section of its exit which is $(2.7 \mathrm{~L})(70 \mathrm{~mm})$ size. The fan is chosen so that the velocity within the duct is limited with small velocity in order to get low Reynolds number giving the chance for a mixed convection to take place when heating the module as will be described latter. The duct is wrapped with a very thin plastic insulation in order to prevent air leakage during fan operation.

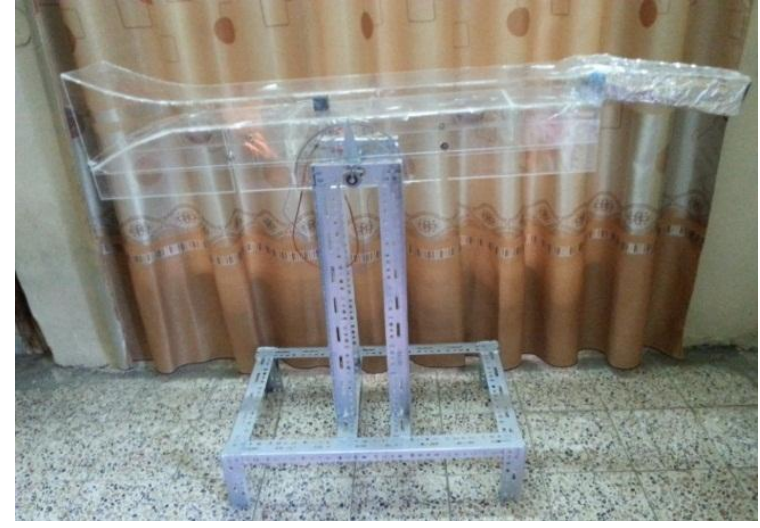

Fig. 1: Test rig with accessories

\subsection{The Electric Module}

The cubic shape electric module is made of Duralamine alloy (Al:90\%, K=177W/m.K). Its side length is of $(30 \mathrm{~mm})$ and its wall is thick enough so that the heat is transferred in constant temperature, constant heat flux due to high thermal conductivity of its material. The module is painted with a black color to get the best thermal image using infrared camera used to measure its temperature to ensure uniform temperature of its surface. Three holes are made at the lower of the module. At the lower surface center a $(8 \mathrm{~mm})$ screwed hole is made to ensure module fixation to the lower duct side and another cavity $(10 \mathrm{~mm})$ diameter flushed with an epoxy resin to ensure preventing electric conductivity to the module inner surface. A special capsule heater of $(201.67 \Omega)$ resistance is inserted to the hole and the rest of the hole is filled with Zinc, epoxy to ensure good conductance to the module walls so that all heat input is to be transferred to the module surface then to the surrounding air during experimental operation of the apparatus. Other small hole $(1 \mathrm{~mm})$ in diameter is used to measure the module temperature using a calibrated thermocouple of K (Komel-Alumel) type.

The lower surface of the module is insulated using a Teflon layer of $(1 \mathrm{~mm})$ thickness $(\mathrm{K}=0.25 \mathrm{~W} / \mathrm{m} . \mathrm{K})$. This is done by using the layer of $(30 \mathrm{~mm})$ Teflon square size glued with a special epoxy resin. This layer is machined to retain the thermocouple, the screw and the electric terminal of the heating module.

\subsection{Measurement Devices}

The measurement devices are used in this study as DC power. supply to supply the input voltage and the current to the heater, Hot Wire Anemometer Digital to measure the air velocity, Power Controller to control the input voltage of the heater, Temperature Recorder to measure the temperature and Thermal Imager.

\section{DATA REDUCTION}

The total heat that is generated by the heater can be calculated as:

$Q_{\text {gen }}=V * I$

Then to calculate the heat transfer coefficient:-

$q=h \cdot A_{s} \cdot\left(T_{s}-T_{\infty}\right)$

The heat transfer coefficient can calculate in transient mode as: 


$$
q+\dot{m}_{A l} \cdot C p_{A l} \cdot \frac{d T}{d t}=h \cdot A_{s} \cdot\left(T_{s}-T_{\infty}\right)
$$

And in mixed mode as:

$q=h \cdot A_{s} \cdot\left(T_{s}-T_{\infty}\right)$

The Rayleigh number is defined as the ratio between the buoyancy force and the viscous force:

$R a=\frac{\beta \cdot g \cdot\left(T_{s}-T_{\infty}\right) \cdot L^{3}}{\vartheta_{\text {air }}^{2}} \cdot \operatorname{Pr}$

To calculate the Nussel number:-

$N u=\frac{\mathrm{h} \cdot \mathrm{L}}{\mathrm{K}_{\mathrm{air}}}$

To calculate the Reynolds number:-

$R e=\frac{v \cdot L}{\vartheta_{\text {air }}}$

\section{RESULTS AND DISCUSIONS}

The purpose of the present work is to study the behavior of cooling rate of an electric module in the shape of a cube put in a long duct to be tilted at different angles. The modes of heat transfer are ransient mode, transferred to mixed or forced convection when moving the air through the duct by a fan fixed at duct end. To verify the effect of buoyancy (natural convection) relative to inertia effect (Re number) effect in mixed convection different heating levels are used (input power). The mixed convection is tested using different air velocities with the duct. The $\mathrm{Gr} / \mathrm{Re}^{2}$ values are used to verify the level of forced (inertia) relative to the natural convection effect.

Figures 3, 4 and 5 gives the variation of Nusselt number with Rayleigh number at different positions of the module $(X / L=5$, $\mathrm{X} / \mathrm{L}=10$ and $\mathrm{X} / \mathrm{L}=15$ ) respectively, when cooling the module by operating the fan and reached the steady state condition with different air velocities represented by Reynolds number of $(\operatorname{Re}=318.9,763.7,954.7,1336.6$ and 1527.5). Figures show that Nusselt number values increases progressively as Rayleigh number increases. The rate of increase is high at low Rayleigh number and tends to reach an asymptotic value when Rayleigh number increases. When the position of the module is at the duct inlet $(\mathrm{X} / \mathrm{L}=5)$ the tilt angle effect is small relatively with the values at $\left(\theta=0^{\circ}\right)$ is the lowest and the values of $\left(\theta=90^{\circ}\right)$ is maximum and other tilt angle values are in between. The same behavior is detected for other module positions $(\mathrm{X} / \mathrm{L}=10$ and $\mathrm{X} / \mathrm{L}=15)$ with the values of Nussult number is the lowest at $\left(\theta=0^{\circ}\right.$ and $\left.\theta=30^{\circ}\right)$ and increases as the tilt angle increases.

Figure 6, 7 and 8 gives Nusselt number variation with Reynolds number for $(\mathrm{X} / \mathrm{L}=5, \quad \mathrm{X} / \mathrm{L}=10$ and $\mathrm{X} / \mathrm{L}=15)$ respectively, when operating the system in transient convection using different heating power for different tilt angles and module position. Figures declare that the variation of Nusselt number is relatively small with tilt angle and the mean variable affecting the heat transfer coefficient is air velocity in the duct and the heating power to the module.

\section{CORRELATIONS}

Nusselt number correlations have been developed with the help of relevant dimensionless groups involving parameters like tilt angles of the duct $\theta, \mathrm{X} / \mathrm{L}$, Reynolds number and Grashof number.

In analyzing the experimental data for the effect of the individual dimensionless group, the values of constant $(\mathrm{K})$ and the exponent (a-d) have been obtained by using LAB fit curve fitting software-version 7.2. The LAB fit is software for windows developed aiming the treatment and the analysis of experimental data and determine propagated error (error propagation up to eight independent variables):

\section{1- For Transient convection}

The correlation of (AD) approach for Nusselt number (at horizontal case) with error of $+10 \%$ and $-10 \%$.

$$
\begin{aligned}
& N u=K \cdot(R e)^{a} \cdot\left(\frac{X}{L}\right)^{b} \cdot\left(G r_{m}\right)^{c} \\
& N u=0.0929 .(R e)^{0.229} \cdot\left(\frac{X}{L}\right)^{0.0389} \cdot\left(G r_{m}\right)^{0.324}
\end{aligned}
$$

The correlation of (DA) approach for Nusselt number (at inclined case) with error of $+11 \%$ and $-11 \%$.

$$
\begin{aligned}
& N u=K \cdot(\operatorname{Re})^{a} \cdot(\theta)^{b} \cdot\left(\frac{X}{L}\right)^{c} \cdot\left(G r_{m}\right)^{d} \\
& N u=0.0924 \cdot(\operatorname{Re})^{0.202} \cdot(\theta)^{0.0356} \cdot\left(\frac{X}{L}\right)^{0.00361} \cdot\left(G r_{m}\right)^{0.353}
\end{aligned}
$$

\section{2- For Mixed/Forced convection}

The developed correlation of Dimensional Analysis (AD) approach for Nusselt number in mixed/forced state (at horizontal case) is as follows with error of $+15 \%$ and $-15 \%$ :

$$
\begin{aligned}
& N u=K \cdot(\operatorname{Re})^{a} \cdot\left(\frac{X}{L}\right)^{b} \cdot(G r)^{c} \\
& N u=0.0099 \cdot(R e)^{0.304} \cdot\left(\frac{X}{L}\right)^{0.0502} \cdot(G r)^{0.472}
\end{aligned}
$$

Developed correlation of Dimensional Analysis (DA) approach for Nusselt number in mixed/forced state (at inclined case) is as follows with error of $+19 \%$ and $-19 \%$ :

$$
\begin{aligned}
& N u=K \cdot(R e)^{a} \cdot(\theta)^{b} \cdot\left(\frac{X}{L}\right)^{c} \cdot(G r)^{d} \\
& N u=0.0133 \cdot(R e)^{0.267} \cdot(\theta)^{0.05} \cdot\left(\frac{X}{L}\right)^{0.0233} \cdot(G r)^{0.479}
\end{aligned}
$$

\section{CONCLUSIONS}

- Heat dissipation rates by mixed convection from electric module represented by the Nusselt number increase with increasing the Reynolds number.

- The effect of the tilt angle of the duct of the heat transfer is small relative, so the tilt angle $\left(\theta=0^{\circ}\right)$ gives a lower value of Nusselt number, but the tilt angle $\left(\theta=90^{\circ}\right)$ gives the higher value in mixed mode.

- In transient convection, the value of Nusselt number is higher when the tilt angle $\left(\theta=45^{\circ} \& \theta=90^{\circ}\right)$ and the effect of electric module position is small.

- Maximum enhancement in heat transfer $\left(\mathrm{EF}_{2}\right)$ is measured to be $48.4 \%$ for $\left(\theta=0^{\circ}\right)$ at $(\mathrm{X} / \mathrm{L}=15$, power $=1.65 \mathrm{~W})$, for $\left(\theta=30^{\circ}\right)$ is $32.8 \%$ at $(\mathrm{X} / \mathrm{L}=5$, power $=0.51 \mathrm{~W})$, for $\left(\theta=45^{\circ}\right)$ is $41.2 \%$ at $(\mathrm{X} / \mathrm{L}=15$, power $=0.51 \mathrm{~W})$ and for $\left(\theta=90^{\circ}\right)$ is $39.2 \%$ at $(X / L=15$, power $=0.51 \mathrm{~W}$ ).

- Maximum enhancement in heat transfer $\left(\mathrm{EF}_{3}\right)$ is measured to be $143.6 \%$ for $\left(\theta=0^{\circ}\right)$ at $(\mathrm{X} / \mathrm{L}=10$, $\operatorname{Re}=1527.5)$, for $\left(\theta=30^{\circ}\right)$ is $100 \%$ at $(X / L=15$, $\mathrm{Re}=1336.6)$, for $\left(\theta=45^{\circ}\right)$ is $119.6 \%$ at $(\mathrm{X} / \mathrm{L}=15$, $\operatorname{Re}=381.9)$ and for $\left(\theta=90^{\circ}\right)$ is $137.1 \%$ at $(X / L=15$, $\mathrm{Re}=381.9$ ). 
- A general formula for correlating the data of the cube inside the duct is presented in the form

*For Transient convection

A) At Horizontal

$N u=0.0929 .(R e)^{0.229} \cdot\left(\frac{X}{L}\right)^{0.389} \cdot\left(G r_{m}\right)^{0.324}$

B) At Inclined

$N u=0.0924 .(R e)^{0.202} \cdot(\theta)^{0.0356} \cdot\left(\frac{X}{L}\right)^{0.00361} \cdot\left(G r_{m}\right)^{0.353}$

* For Mixed/Forced convection

\section{A) At Horizontal}

$N u=0.0099 .(R e)^{0304} \cdot\left(\frac{X}{L}\right)^{0.0502} \cdot\left(G r_{m}\right)^{0.472}$

B) At Inclined

$N u=0.0133 .(R e)^{0.267} \cdot(\theta)^{0.05} \cdot\left(\frac{X}{L}\right)^{0.233} \cdot\left(G r_{m}\right)^{0.479}$

\section{RECOMMANDATIONS}

1-Taking multi cubes condition.

2- Using shorter duct.

3- Using a ribbed duct to verify the heat transfer enhancement.

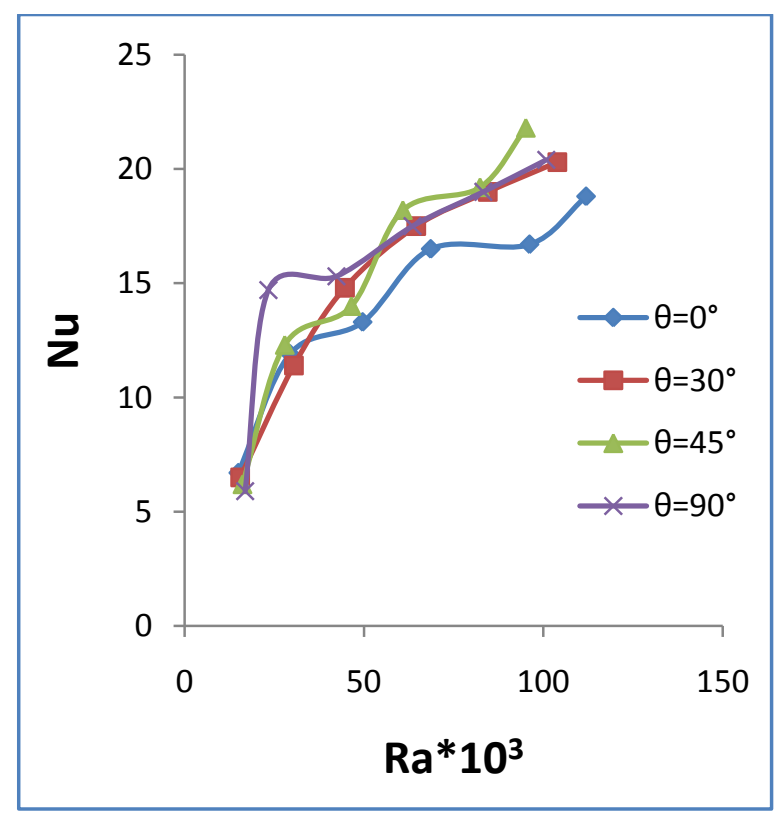

(a)

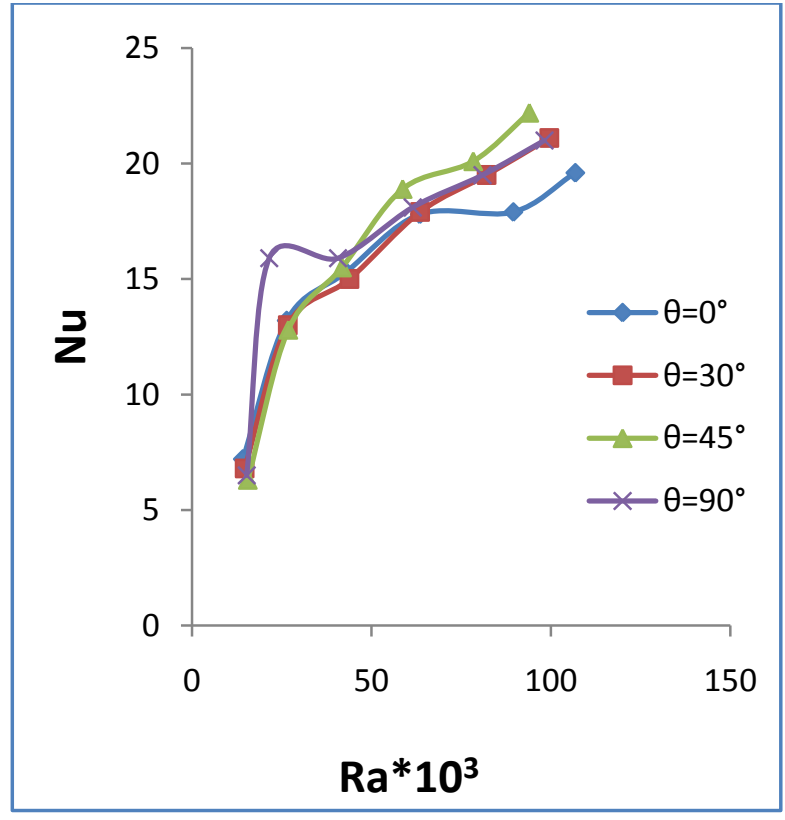

(b)

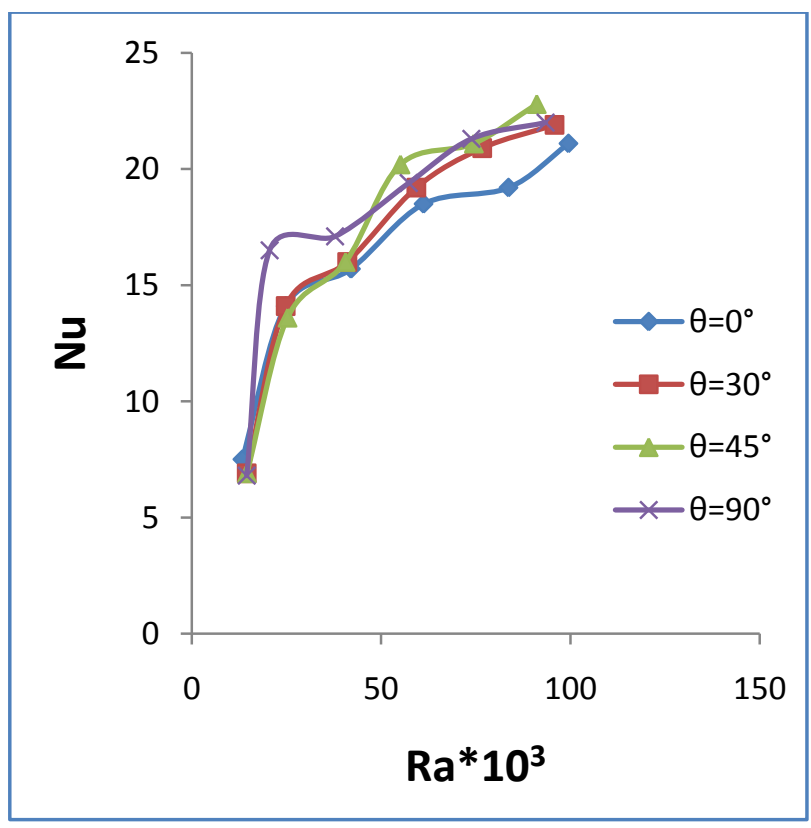

(c) 


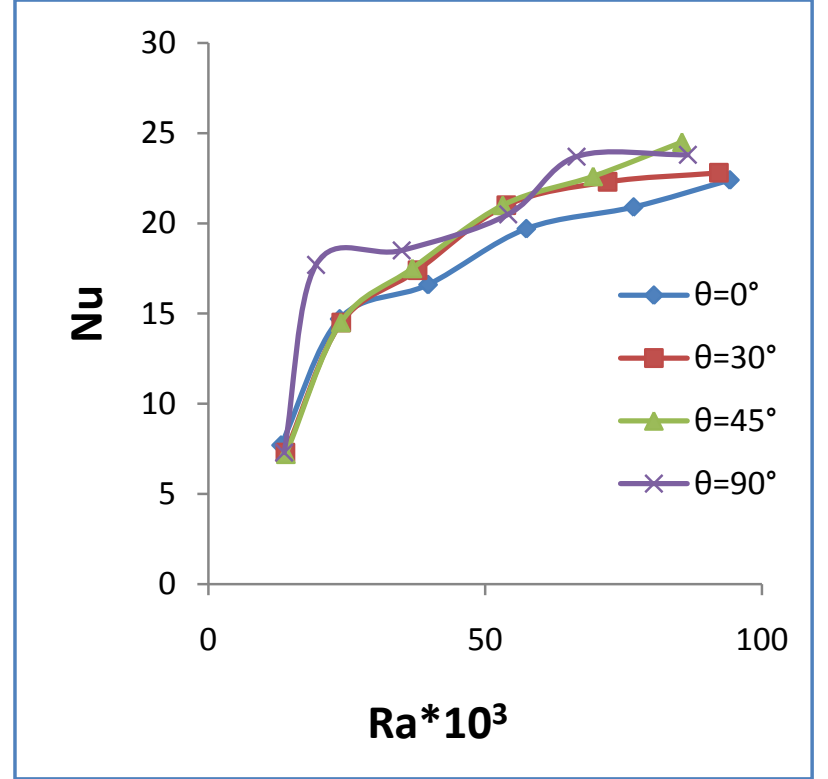

(d)

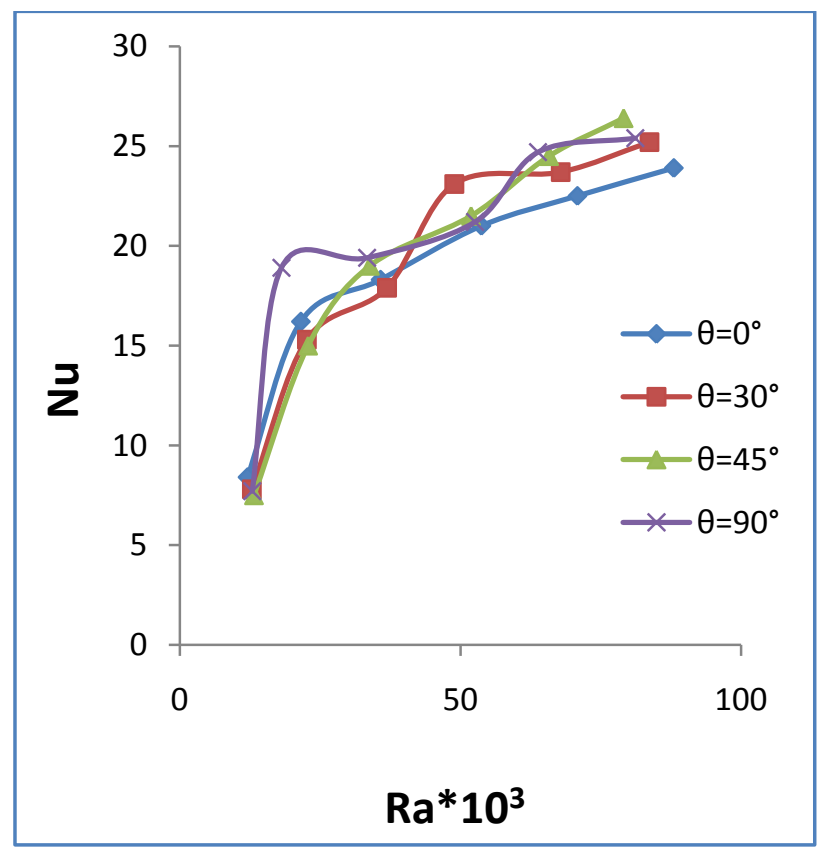

(e)

Figure 3: Variation of Nusselt number with Rayleigh number at $\mathrm{X} / \mathrm{L}=5$ (forced convection)

$\begin{array}{lll}\text { a) } \operatorname{Re}=381.9 & \text { b) } \operatorname{Re}=763.7 & \text { c) } \operatorname{Re}=954.7\end{array}$

d) $\operatorname{Re}=1336.6$ e) $\operatorname{Re}=1527.5$

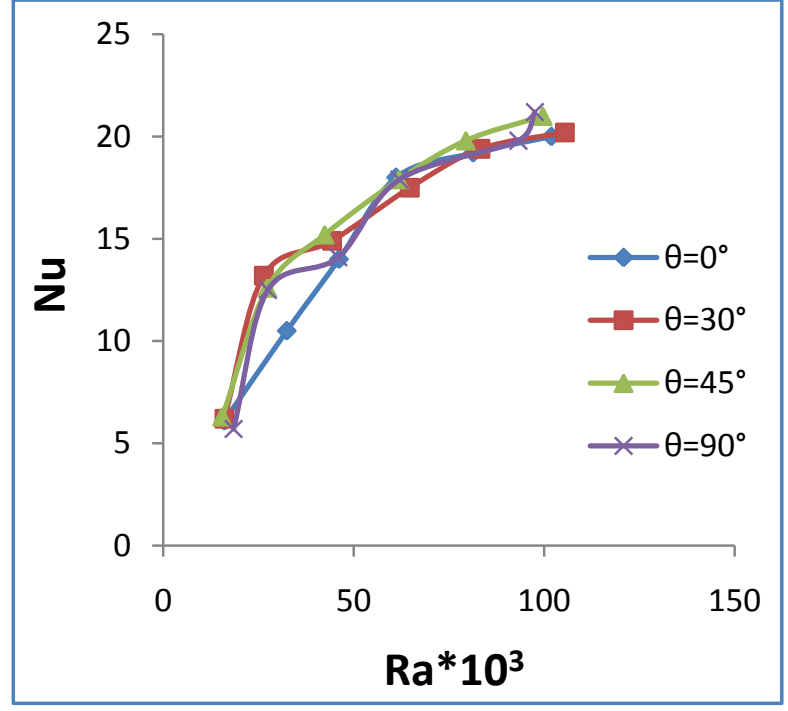

(a)

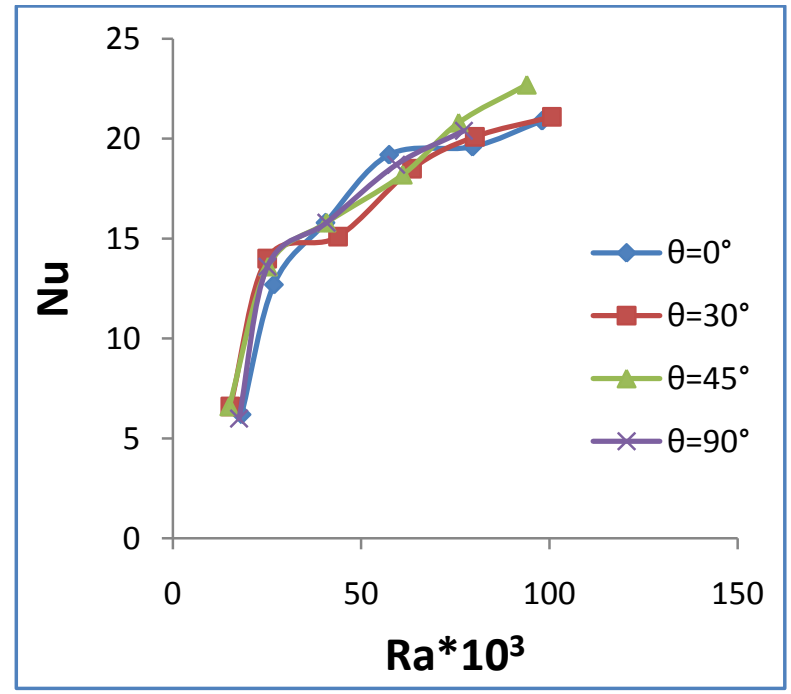

(b)

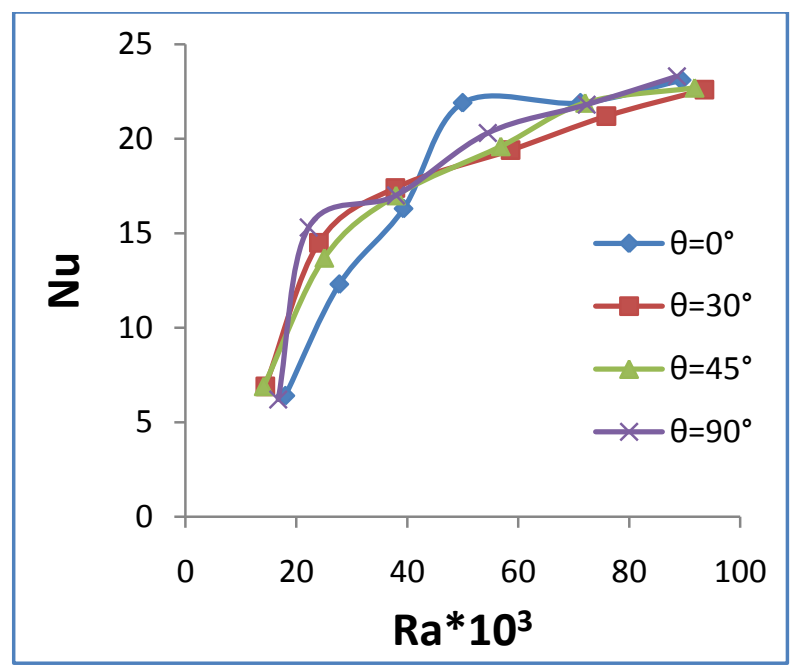

(c) 


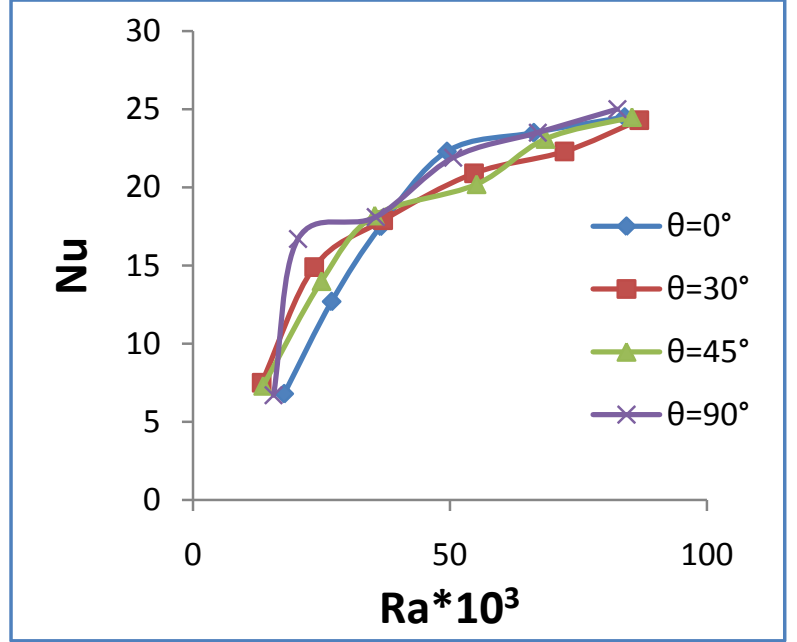

(d)

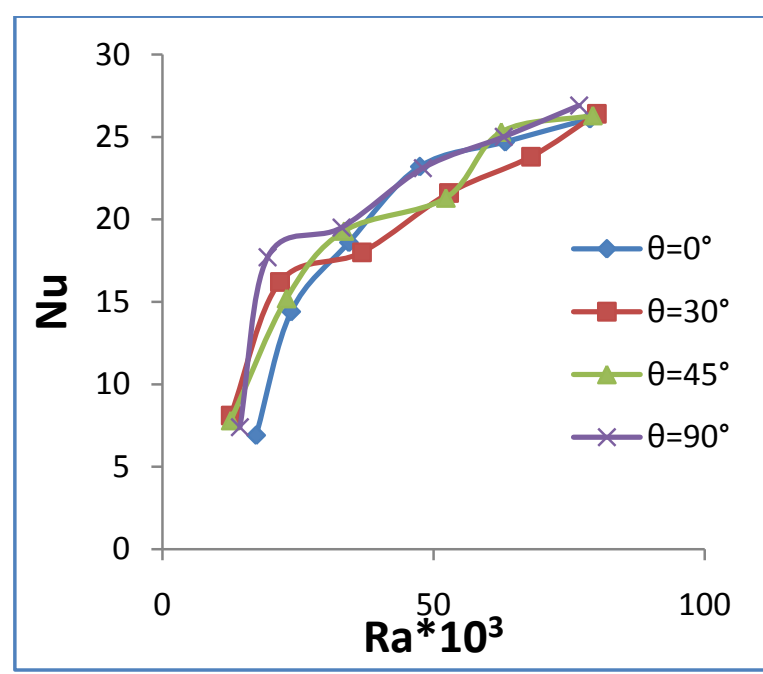

(e)

Figure 4: Variation of Nusselt number with Rayleigh number at $X / L=10$ (forced convection)

$\begin{array}{lll}\text { a) } \operatorname{Re}=381.9 & \text { b) } \operatorname{Re}=763.7 & \text { c) } \operatorname{Re}=954.7\end{array}$

d) $\operatorname{Re}=1336.6$ e) $\operatorname{Re}=1527.5$

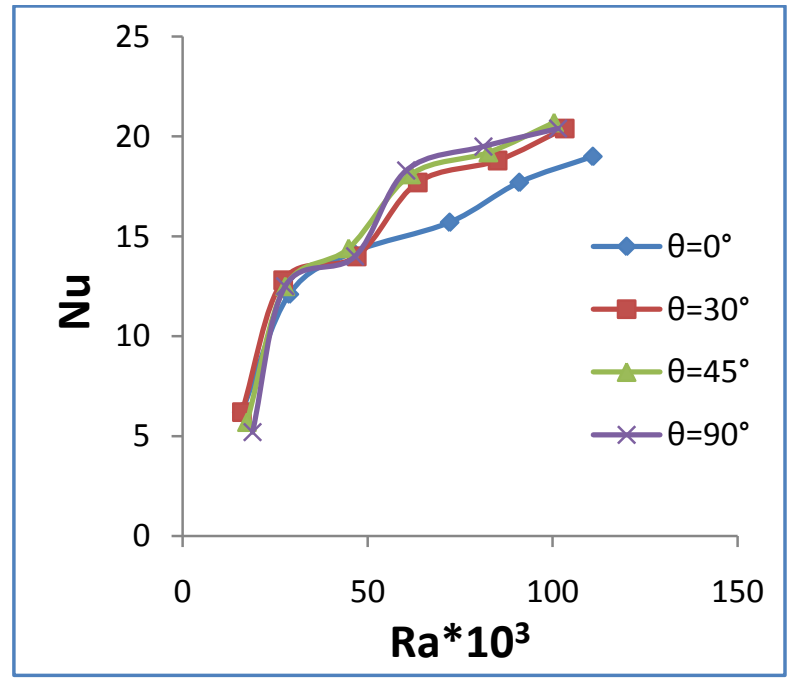

(a)

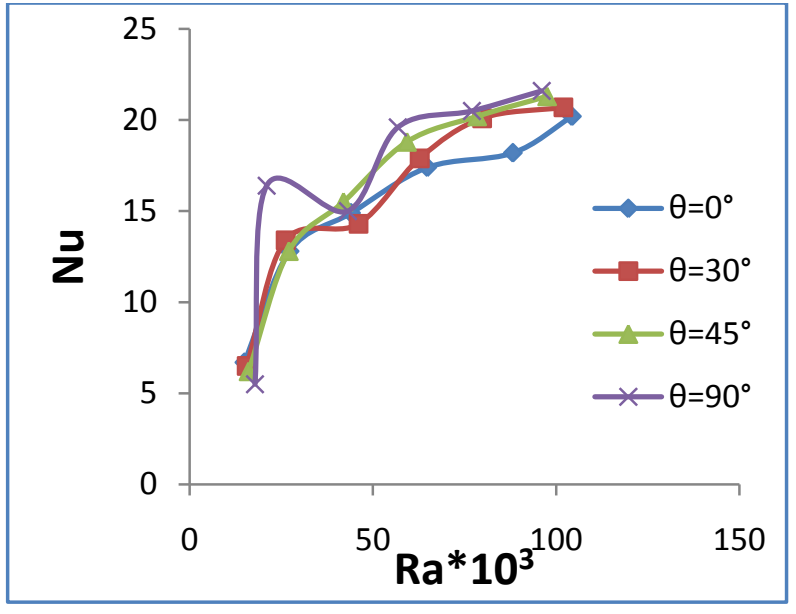

(b)

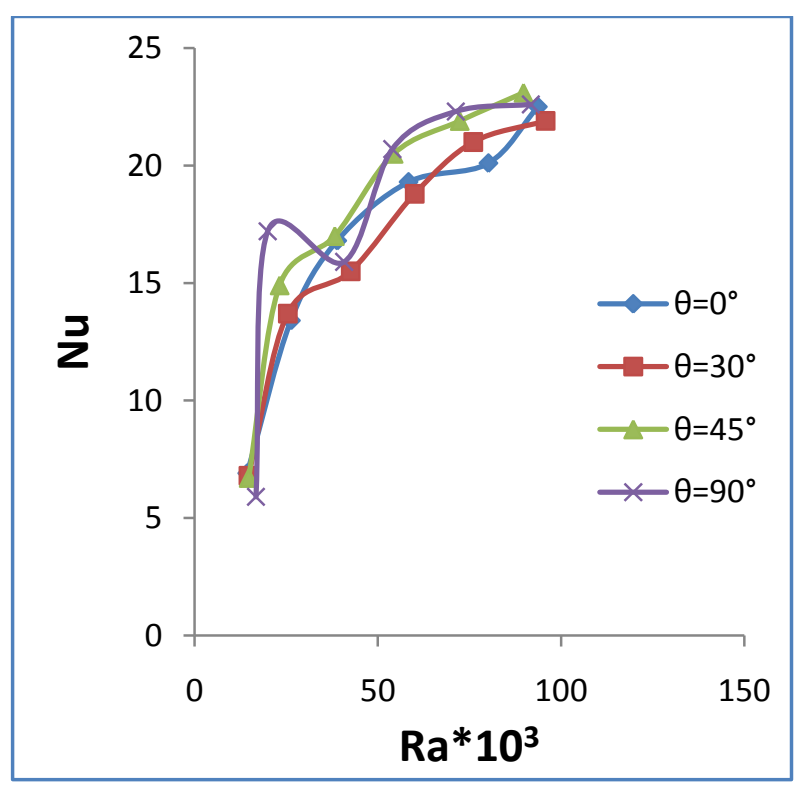

(c)

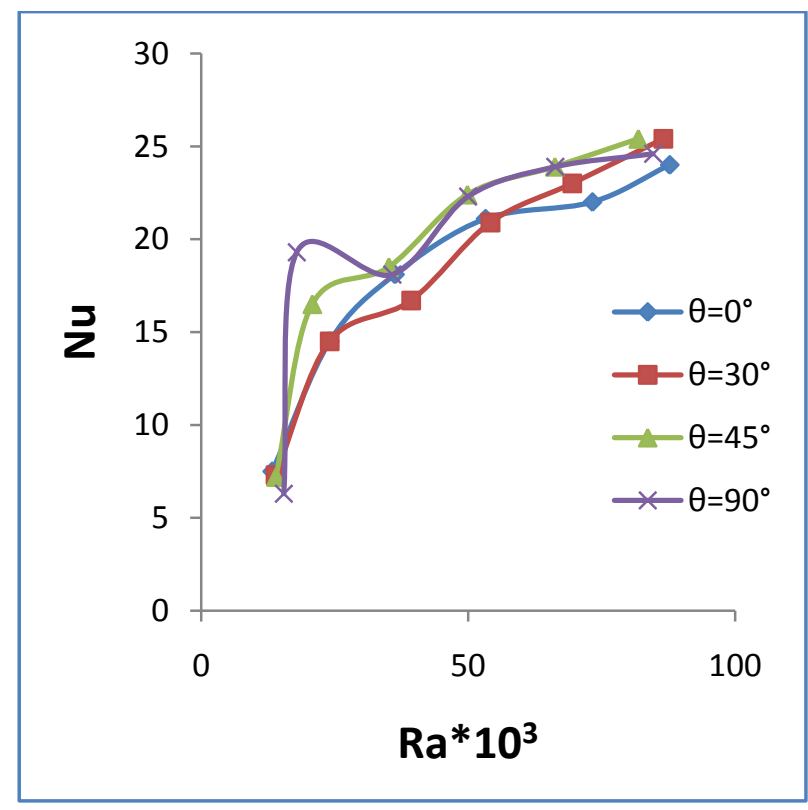

(d) 


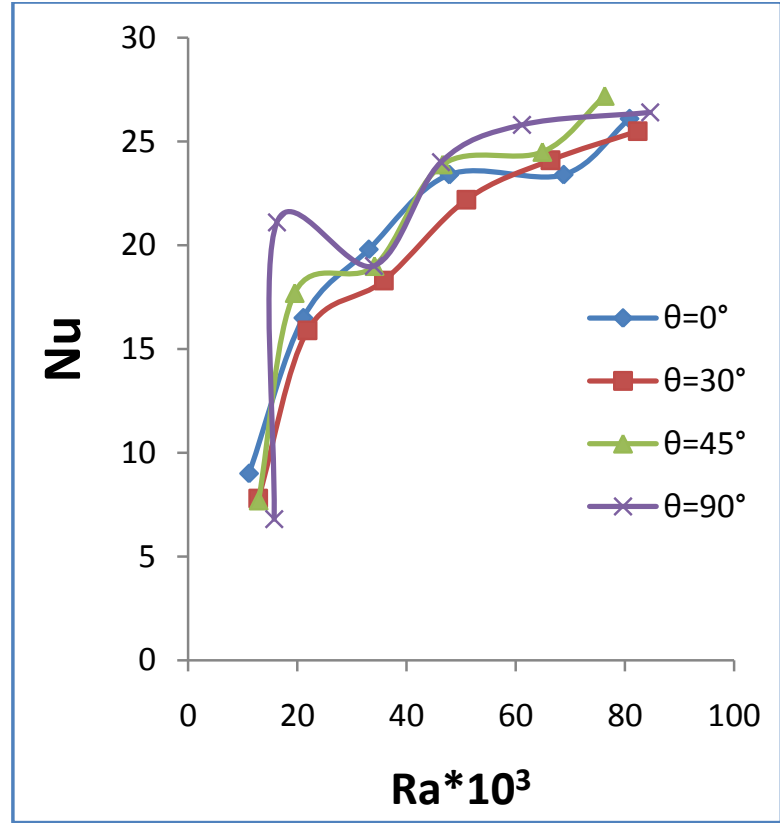

(e)

Figure 5: Variation of Nusselt number with Rayleigh number at $X / L=15$ (forced convection)

$\begin{array}{lll}\text { a) } \operatorname{Re}=381.9 & \text { b) } \operatorname{Re}=763.7 & \text { c) } \operatorname{Re}=954.7\end{array}$

d) $\operatorname{Re}=1336.6$ e) $\operatorname{Re}=1527.5$

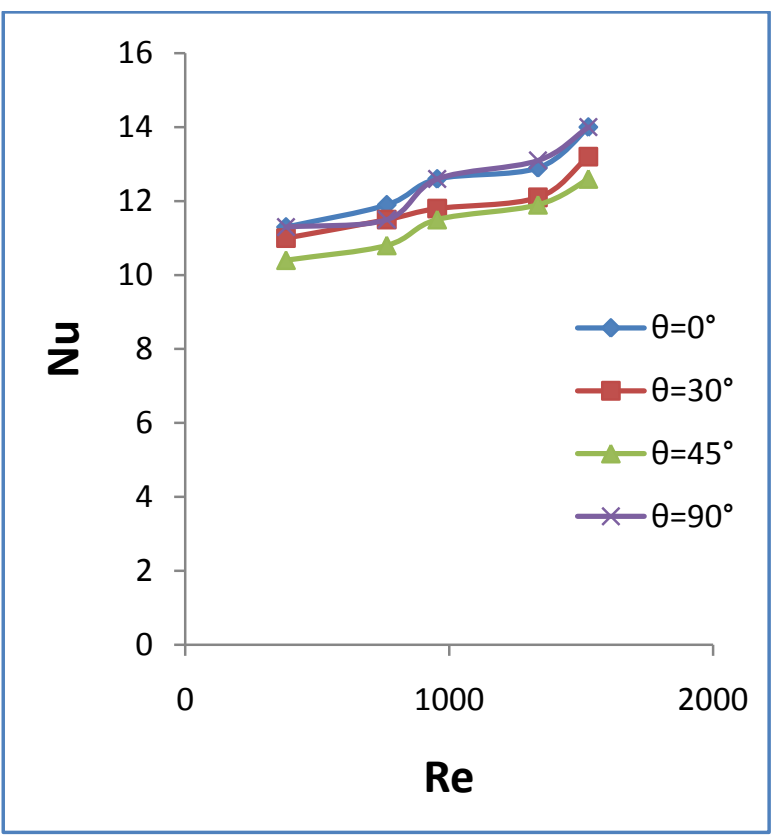

(a)

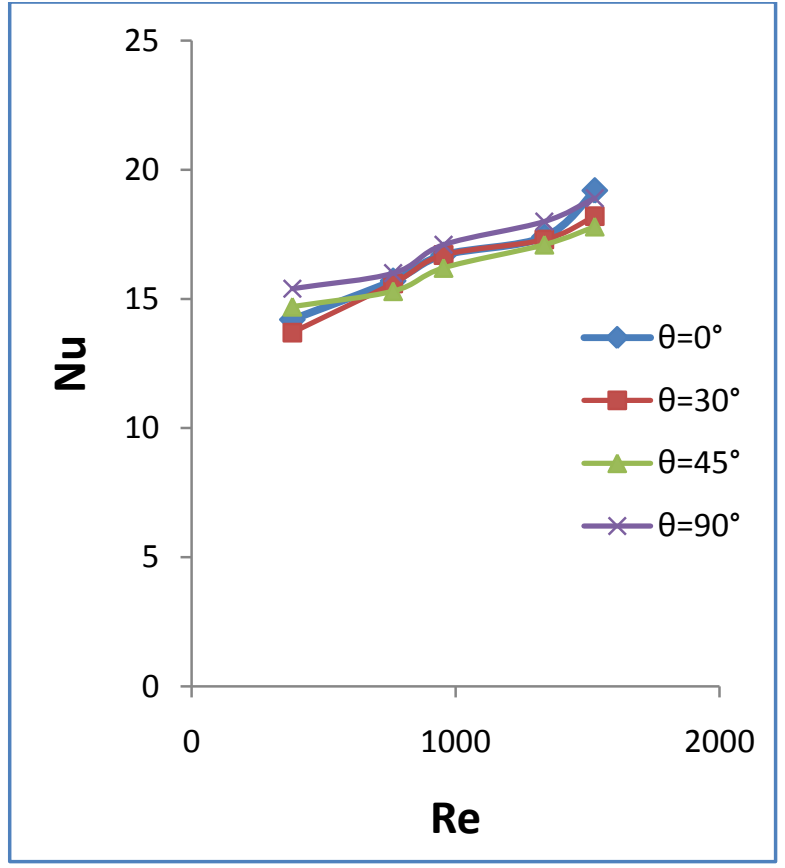

(b)

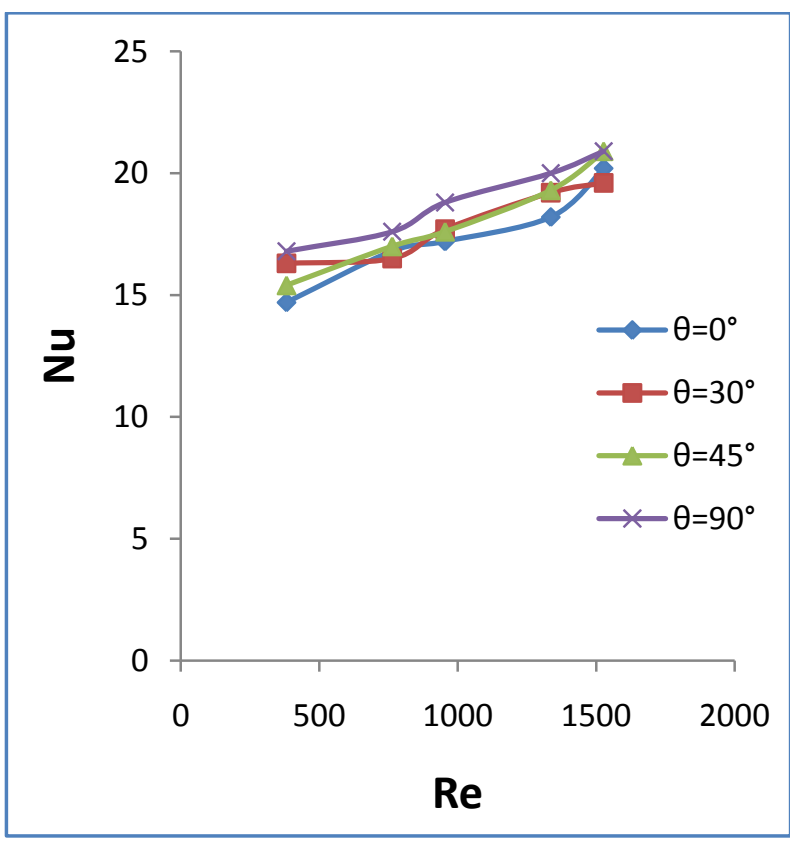

(c) 


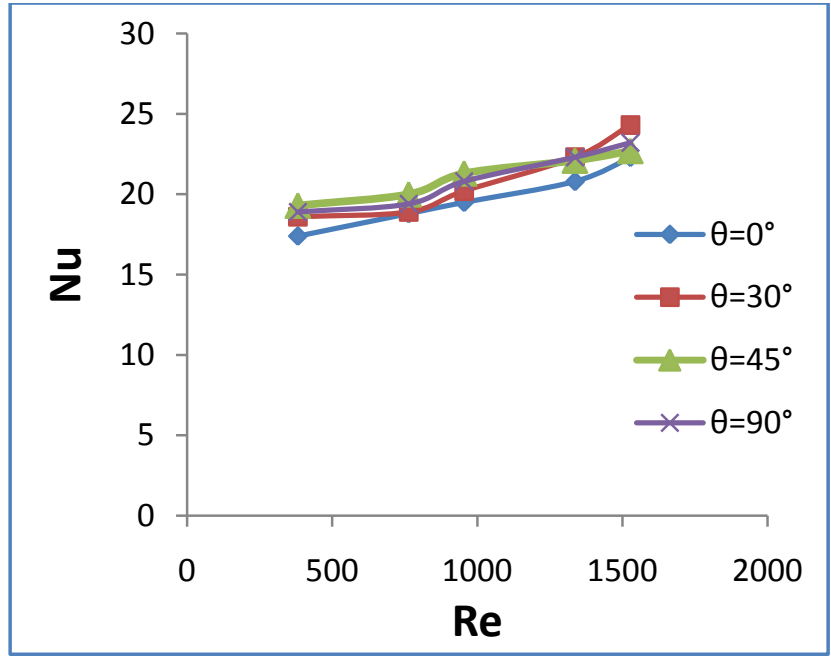

(d)

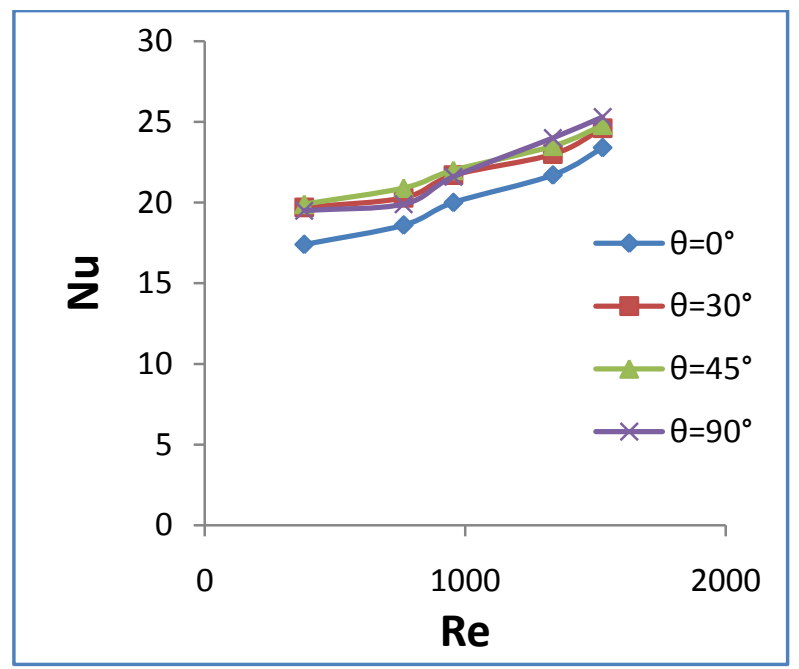

(e)

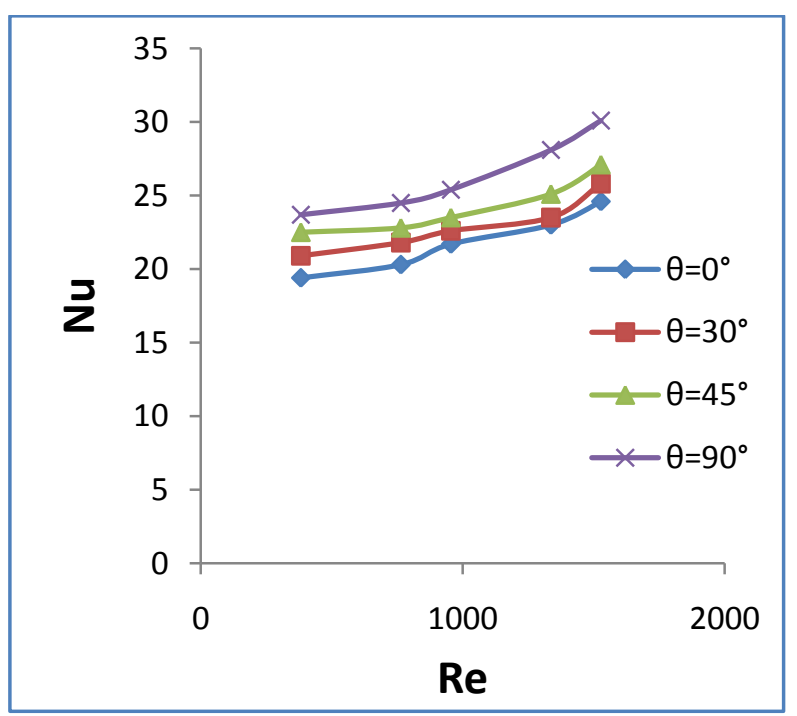

(f)

Figure 6: Variation Nusselt number with Reynolds number at $\mathrm{X} / \mathrm{L}=5$ (Transnet convection)
a)power $=0.147 \mathrm{~W}$
b)power $=0.51 \mathrm{~W}$
c)power $=0.96 \mathrm{~W}$
d)power $=1.65 \mathrm{~W}$
e)power $=2.34 \mathrm{~W}$
f)power $=3.075 \mathrm{~W}$

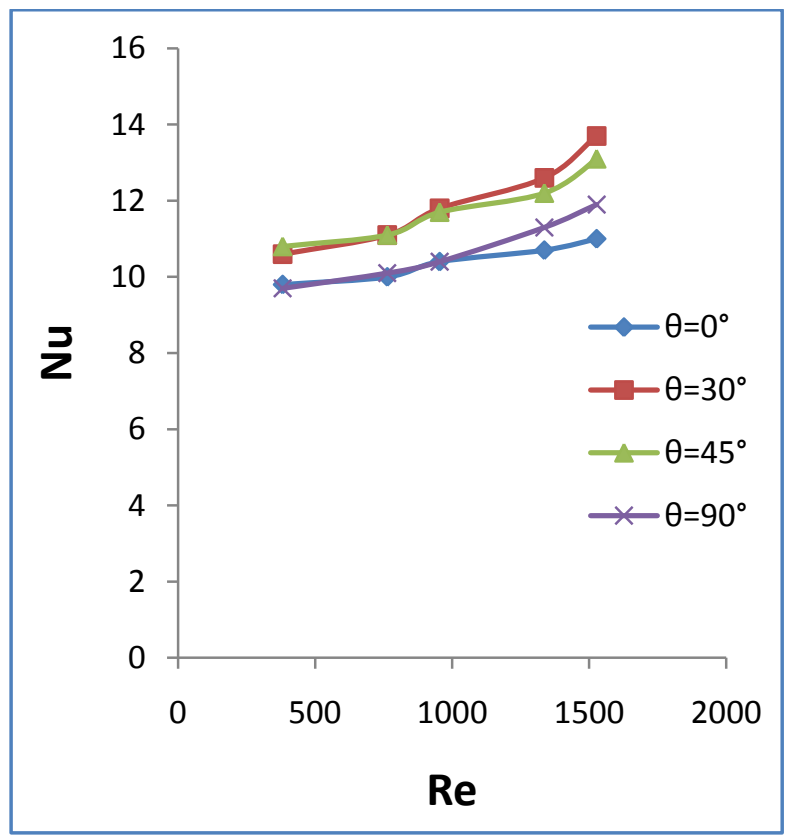

(a)

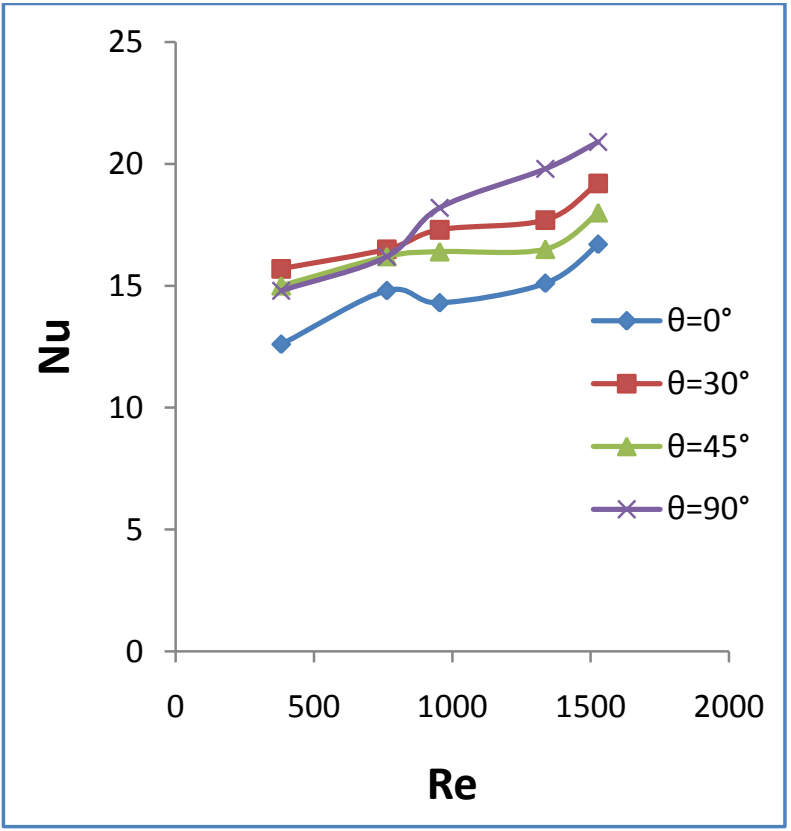

(b) 


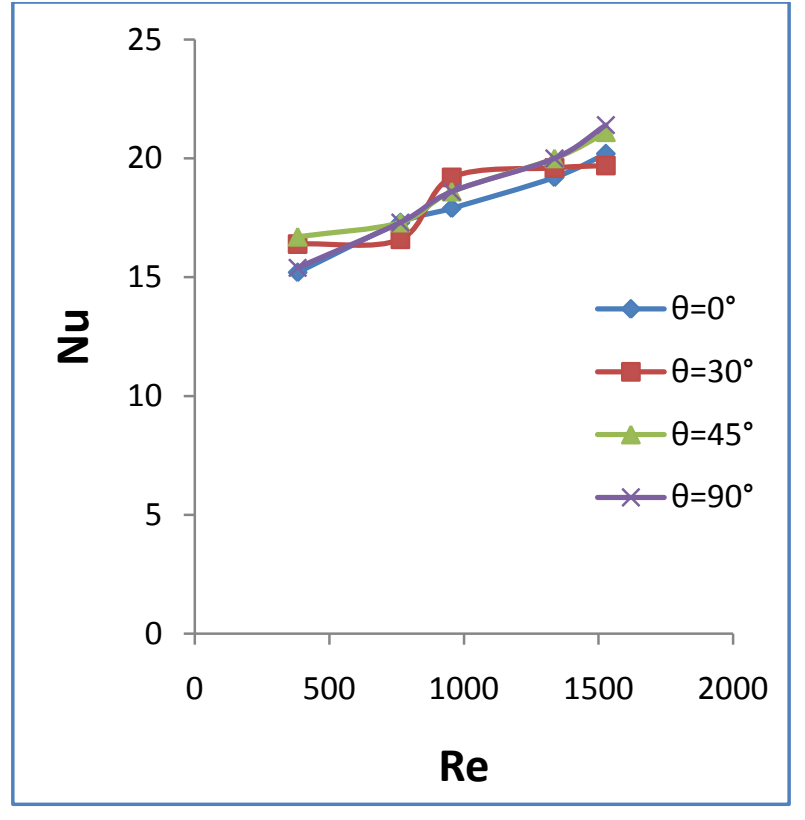

(c)

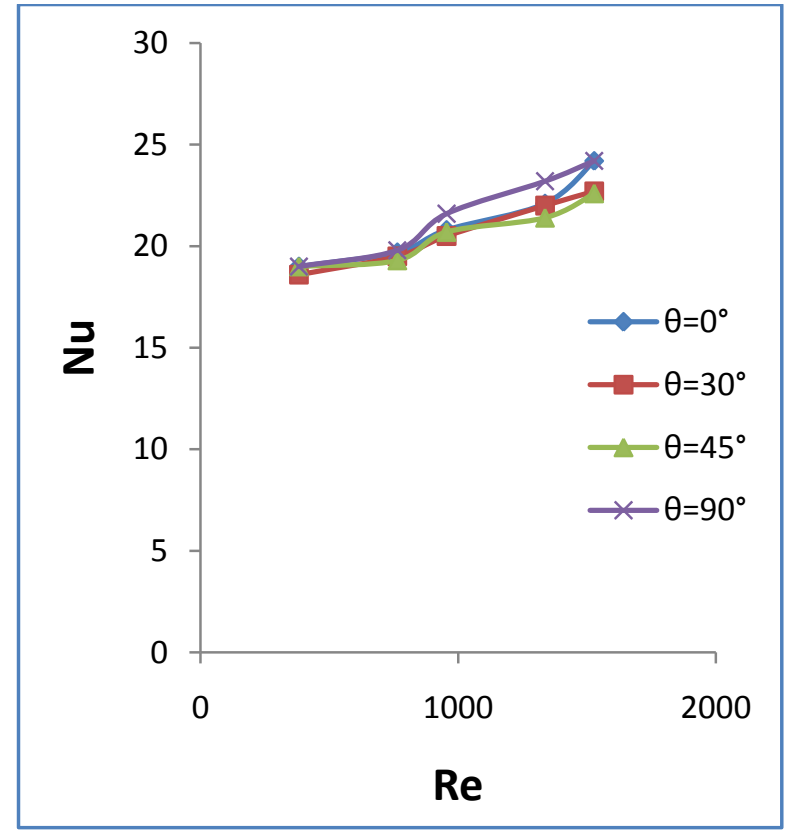

(d)

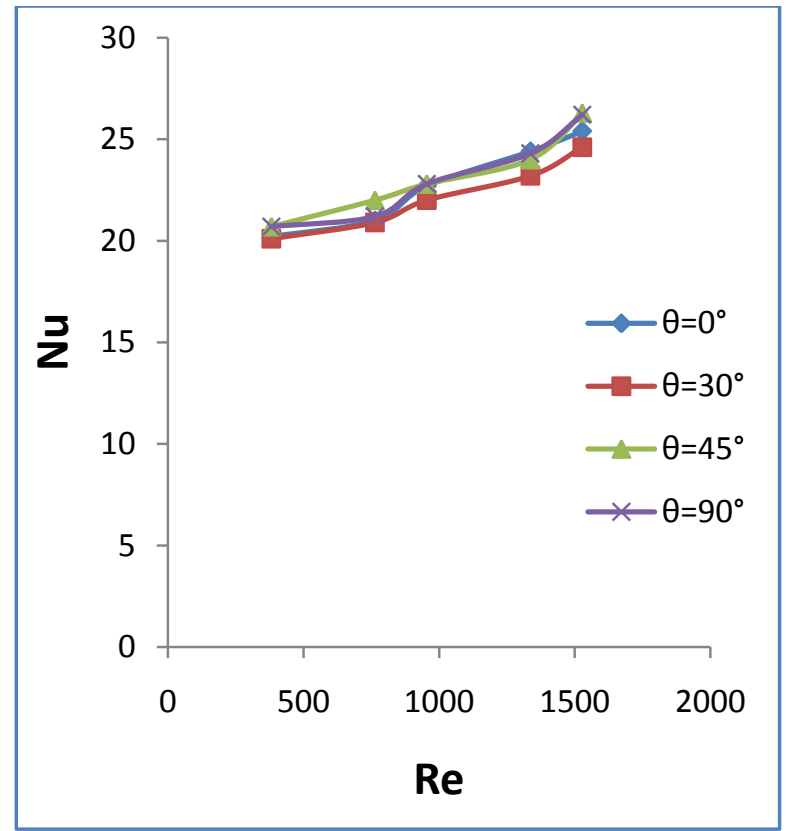

(e)

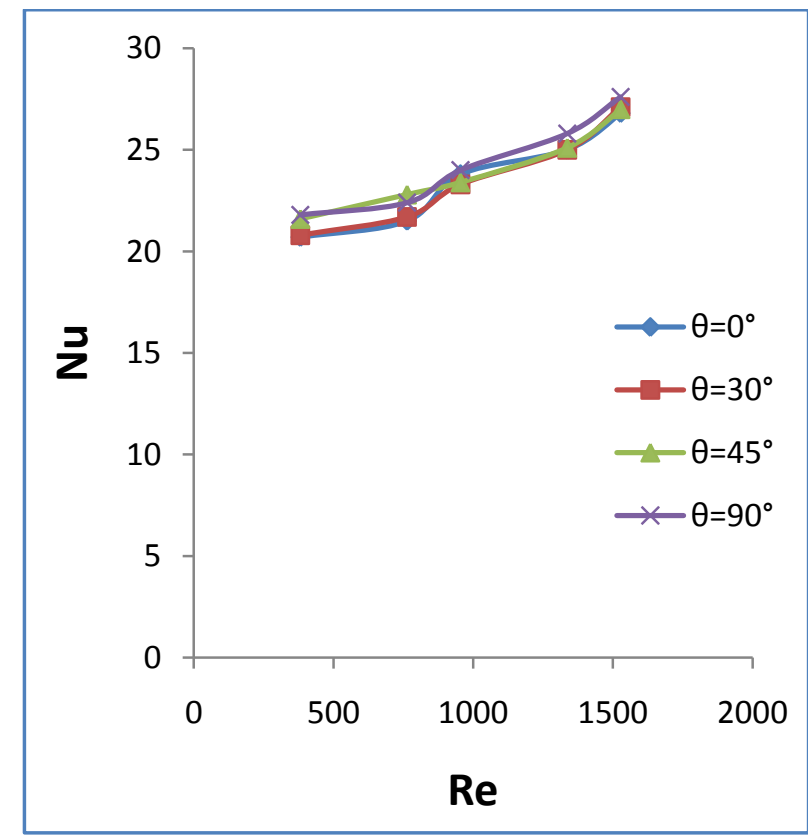

(f)

Figure 7: Variation Nusselt number with Reynolds number at $\mathrm{X} / \mathrm{L}=10$ (Transnet convection)

a)power $=0.147 \mathrm{~W}$

c)power $=0.96 \mathrm{~W}$

e)power $=2.34 \mathrm{~W}$ b)power $=0.51 \mathrm{~W}$

d) power $=1.65 \mathrm{~W}$ f)power $=3.075 \mathrm{~W}$ 


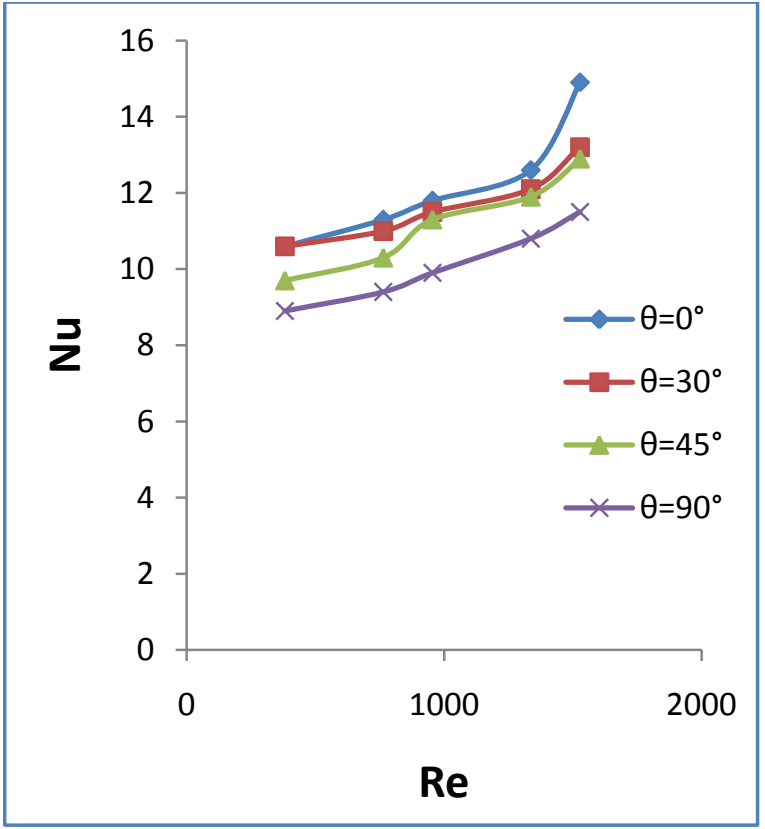

(a)

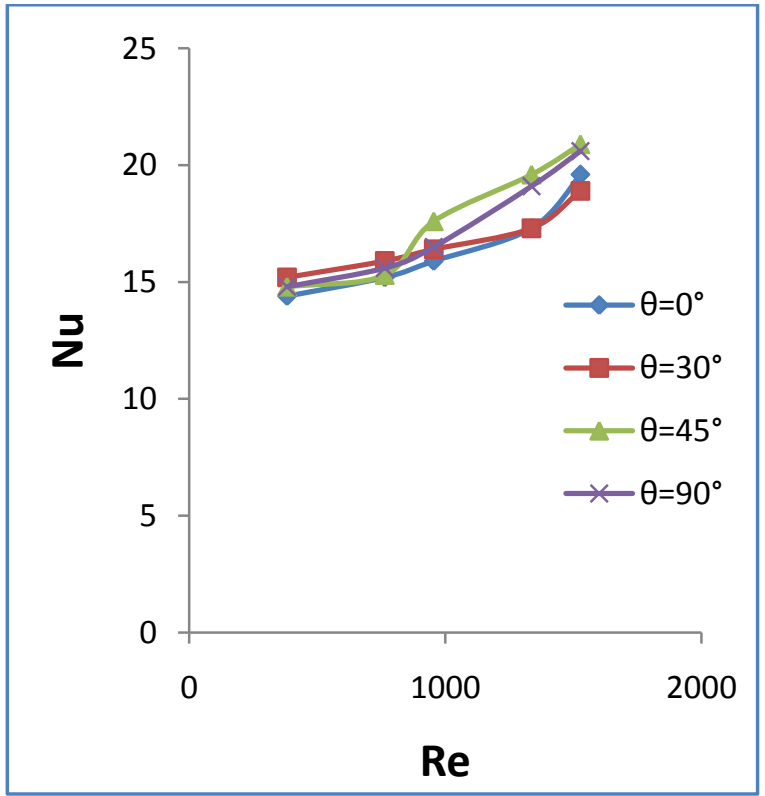

(b)

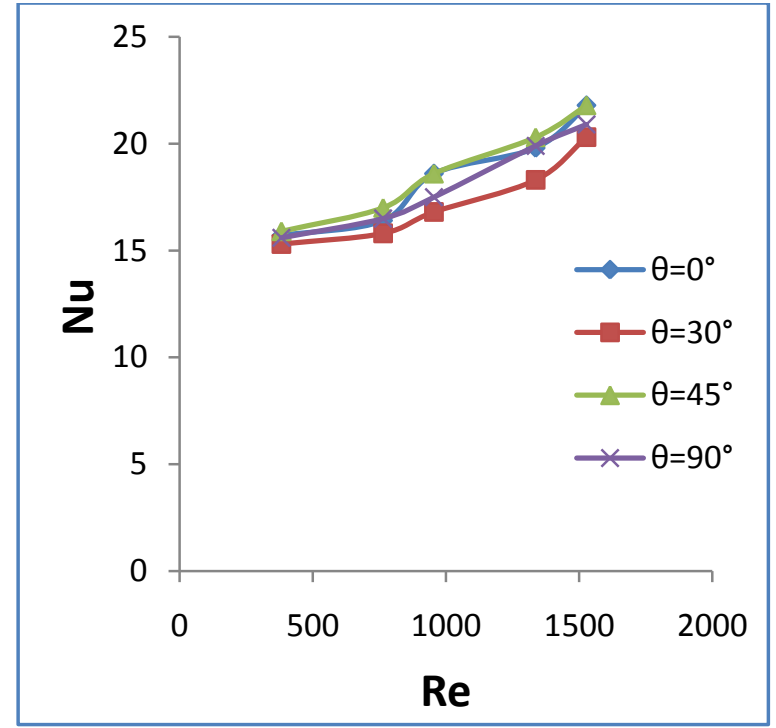

(c)

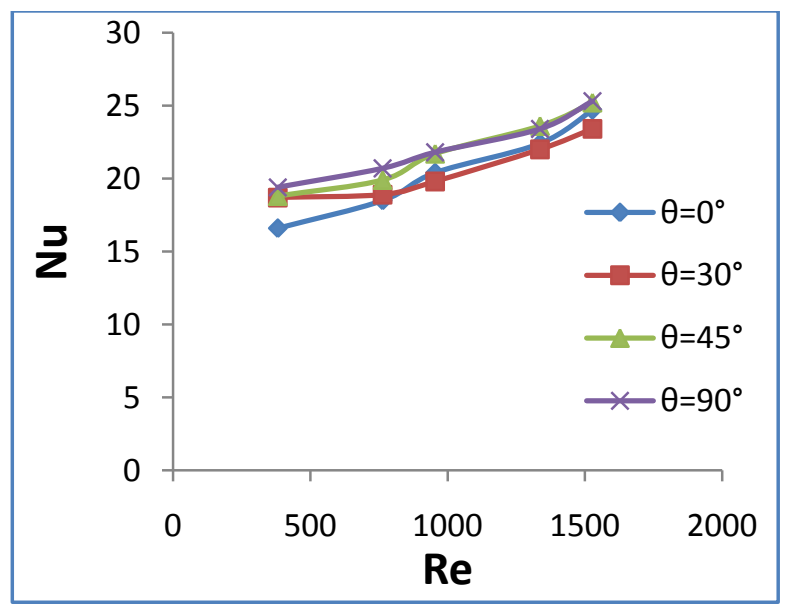

(d)

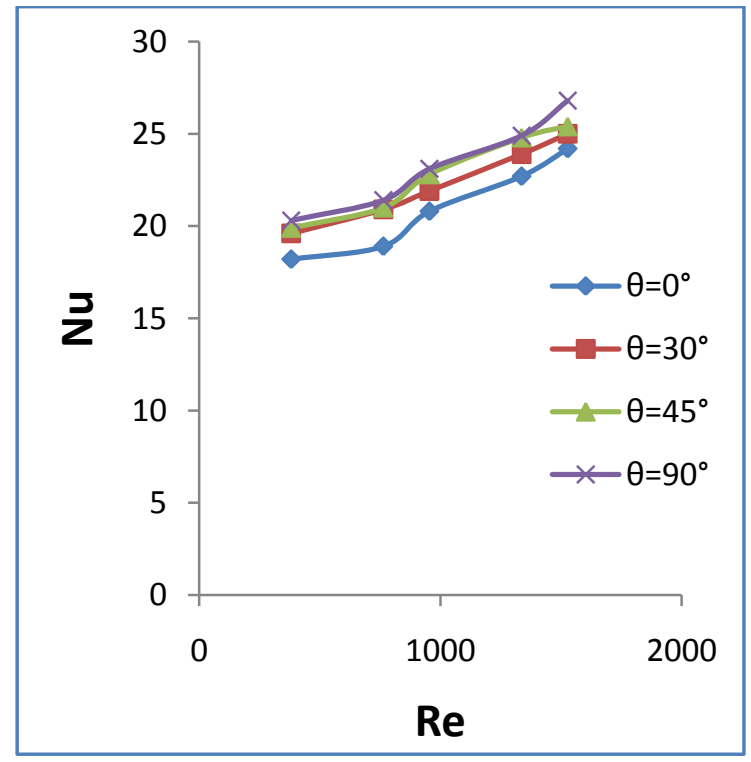

(e) 


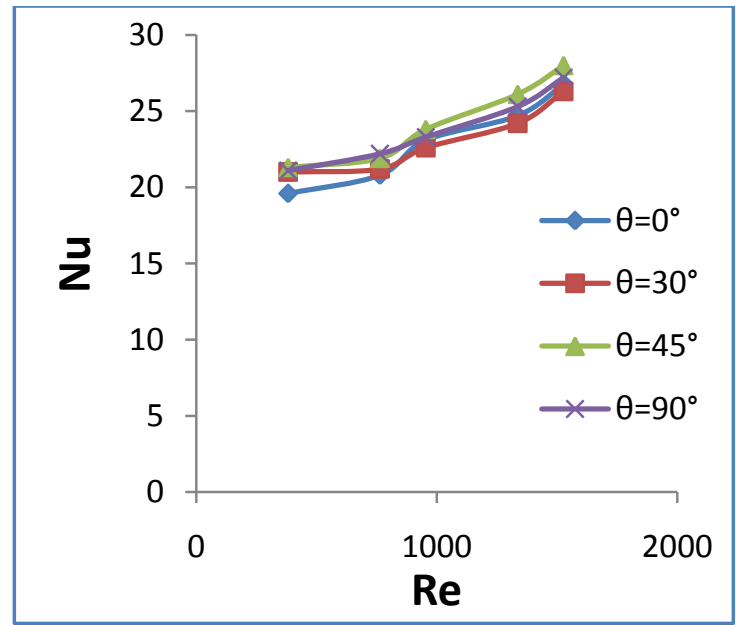

(f)

Figure 8: Variation Nusselt number with Reynolds number at $\mathrm{X} / \mathrm{L}=15$ (Transnet convection)

$\begin{array}{lll}\text { a)power }=0.147 \mathrm{~W} & \text { b)power }=0.51 \mathrm{~W} & \text { c)power }=0.96 \mathrm{~W} \\ \text { d)power }=1.65 \mathrm{~W} & & \text { e)power }=2.34 \mathrm{~W} \\ \text { f)power }=3.075 \mathrm{~W} & & \end{array}$

\section{REFERENCES}

[1] Weilin Qu, Issam Mudawar, "Analysis of threedimensional heat transfer in micro-channel heat sinks', International Journal of Heat and Mass Transfer 45 (2002) 3973-3985.
[2] F.P. Incropera, D.P. Dewitt, T.L. Bergman and A.S. Lavine, "Fundamentals of the heat and mass transfer", Wiley, $7^{\text {th }}$ edition, 2011.

[3] Shakuntala Ojha, 'CFD Analysis on Forced Convection Cooling of ELECTRONIC Chips', Master thesis, National Institute of Technology Rourkela 2009.

[4] W. S. Kim and M. N. Ozisik, " Transient laminar forced convection in ducts with suddenly applied uniform wall heat flux", int. J. Heat Mass Transfer. Vol. 30, No. 8, pp. 1753-1756, 1987.

[5] M. N. Özisik and R. L. Murray, on the solution of linear fiffusion problems with variable with variable boundary condition Parameters, J. Heat Transfer 96, 48-51 (1974).

[6] KUAN-TZONG LEE and WEI-MON YAN, " Mixed convection heat transfer in horizontal rectangular ducts with wall transpiration effects", 1 11. J. Heat Maw Transfer. Vol. 41, No. 2, 411423, 1998.

[7] Han-Chieh Chiu ${ }^{\text {a }}$, Jer-Huan Jang ${ }^{\text {a }}$ and Wei-Mon Yan ${ }^{\text {b,* }}$, "Combined mixed convection and radiation heat transfer in rectangular ducts rotating about a parallel axis" , International Journal of Heat and Mass Transfer 50 (2007) 4229-4242.

[8] Mohamed Ahmed Saleh, "Investigation of flow and heat transfer in a rectangular channel with discrete rib mounted heat sources on two opposite walls", 5th WSEAS Int. Conf. on Heat and Mass transfer (HMT'08) , Acapulco, Mexico, January PP. 25-27, 2008. 